formed on which the leading medical men have places. When a British soldier has been bitten by a rabid dog the Indian Government has very generously been at the expense of sending the patient to Paris for treatment, but it would be impossible for the Government to do this for all those of its 250 millions of subjects who might require it. The scheme is estimated to cost ten lakhs of rupees and the aid of those interested in India is solicited.

\section{HOMES IN THE HILLS.}

A home in the hills for lady nurses employed in military hospitals in India an officers' hospital or convalescent home in connexion therewith were to be opened this month at Murree and Kasauli. The formation of an institution of this kind originated, we believe, with Lady Roberts. The patients will have the advantage of skilled nursing at very moderate terms, and these homes should supply a need that has been long felt by sick and convalescent officers proceeding to the hills for the recovery of their health after sickness in the plains. There is no need to dwell upon the importance of skilled nursing in such diseases as typhoid fever, for example, because it is universally recognised. The absence of trained nurses in India was often a subject of much difficulty and distress to medical officers in the treatment of their cases. Moreover, it was occasionally almost equally important to be able to send a sick officer to some place in the cooler atmosphere of the hills where his requirements could be supplied and he could also be kept under observation at the same time. We are glad to say that the young off ser now serving in India is far better off in both these respects than he was a few years ago.

\section{Cortespondente.}

\section{"Audi alteram partem."}

\section{"DEFTNITION OF PUERPERAL FEVER." To the Editors of THE LANCET.}

Sins,--The questions which Mr. Morris has raised with reference to puerperal fever and its notification seem to me to be worthy of more than cursory notice. They raise important points as to (1) the exact nature of puerperal fever, and (2) the position of sanitary authorities with regard to its notification.

1. Strictly speaking, of course, the term "puerperal ferer denotes any condition accompanied by rise of temperature during the puerperal period; but of these conditions it is usual to exclude those connected with diseases common to the lying-in and other periods. Rises of temperature connected with lactation and morbid conditions of the breasts are not unfrequently included, more because the genesis of the fever is not traced to its foundation than for any valid reason. Excluding these classes of cases, there can be little doubt that the main cause of rise of temperature in the lying-in state is sepsis. Now according to some authorities there is autogenetic puerperal fever and heterogenetic. Let me pause and consider the situation. The fission fungi-members of which group are known definitely in some cases to be disease producers and are suspected in others, often with very good reason-have a definite place in nature's economy; they are the agents of change, their function being that of breaking up dead vegetable and animal material to render it fit for the use of the higher plants. The uterus more especially, and the genital passages to a less extent, after delivery undergo the processes of waste and repair ; and not only are the products of these present, products which normally are absorbed in the body or are thrown out in the discharges, but not unfrequently fragments of tissue, greater or less, remain which ought to have been got rid of after the delivery of the child. Hence it may be stated that in every case of delivery a woman possesses a nidus for the growth of one or other of the fission fungi either in greater or less degree, and it is on this basis of fact that the foundation of antiseptic midwifery is laid. Puerperal fever, then, is autogenetic in so far as delivery implies the existence of a nidus, and is heterogenetic in so far as the active agent of disease comes from without. The limits of a letter such as this forbid me to enter the fertile field of discussion, which naturally here arises, as to the various clinical phenomena connected with puerperal fever, their explana- tion and origin. For my present purpose all I wish to establish is that the disease which the law requires to be notified is one due to infection from without, and that any fever occurring in the lying-in period, exclusive of those excepted above, is notifiable as puerperal fever-reading the terms of the Act strictly.

2. The position to be taken up by the sanitary authority and its officials is one of some difficulty, as indeed it often is in connexion with other notifiable diseases. Medical officers of health, I venture to think, not unfrequently take up a wrong position with regard to cases of infectious disease in which all the symptoms necessary for a definite classification of the disease are not present at the time of their visit, and very likely were not when medical aid was first called. Cases such as these, often met with early in the outbreak of epidemics, at all events merit careful investigation and observation, and ought not to be treated lightly by sanitary officials. So with regard to puerperal fever, cases, howerer slight, ought to be notified and watched.

Mr. Morris, again, raises the vexed question as to the forbidding of midwives to follow their calling after attending a case of puerperal fever. Personally I have no doubt that it is unnecessary to do so if the mid wife understands what antiseptic precautions are. It is my experience, however, to find that there are a great many mid wives, male and female, who do not. If the female midwife is to be placed under a ban, why not the male also? And here comes the crux. It is possible for a person to be attending at the same time septic cases of any kind, or even to be doing post-mortem work, and confinements without risk to the women, and it is done every day by many men in practice. Without a proper appreciation of the details of antiseptic precautions on the part of the attendant there is, however, a great risk in attending the lying-in woman. It appears to me, then, that the advice on this point to be given to a sanitary authority by a medical officer would vary with the case and its conditions, and must depend upon thorough knowledge of the facts and his own judgment.

Hatfleld, April 23rd, 1893. I am, Sirs, yours truly, Lovell Drage.

\section{DEATH UNDER ETHER.}

\section{To the Editors of $\mathrm{TH} \mathbf{\mathrm { E }} \mathrm{LAN \textrm {AT }}$.}

SIRS, - An inquest was held at this infirmary on the 4th inst. respecting the death of a man aged fifty-six, who wais admitted here suffering from laryngeal obstruction, which necessitated tracheotomy. Ether was administered by means of Clover's inhaler, the indicator never being turned beyond No. 1. The pulse improved at first, but after from four to five minutes it became weaker and slower. The anæsthetic was discontinued, but the heart's action ceased; respiration occurred after the pulse had failed. There wero no signs of asphyxia; the countenance was pale. The medical super. intendent did not perform the operation, as the symptoms pointed to syncope rather than asphyxia. Every means, including artificial respiration, galvanism, subcutaneous injection of ether were tried, but in vain. At the post-mortem examina, tion we found the heart pale, enlarged and flabby, showing signs of fatty degeneration, there was some dilatation and considerable atheromatous disease of the arch and thoracio aorta. The larynx was œdematous ; all other organs healthy. In consequence of the patient being very nervous and difficult to manage, a general anæsthetic was considered desirable as distinguished from a local one-e.g., cocaine-and having regard to the weak condition of the heart $\epsilon$ ther was chosen in preference to chloroform. The case is at once interesting and obscure in that death occurred from syncope during the inhalation of ether. I think it ought to be recorded, and renture to hope you may find room for it in jour next issue. I am, Sirs, yours faithfully,

\section{ARTHUR CHILCOTT,}

Assist. Medical Office

St. Mary Abbotts' Infirmary, Kensington, W., April 24th.

\section{"DEATH CERTIFICATION."}

\section{To the Eaitors of THE LANCET.}

SIns,_- "If it were the case that a fee of half a crown would cost between $£ 60,000$ and $£ 70,000$ annually, then I would put aside the question of fee." So said Dr. Danford Thomas the other day before the Committee on death certification. On the other hand, Sir Spencer Wells declared that 